any other mental illness.

Despite selection for protection against schizophrenia, the condition has persisted but it's unclear why. Many of schizophrenia's symptoms, such as experiencing auditory hallucinations and jumbling sentences, involve brain regions tied to speech, says Bernard Crespi, an evolutionary biologist at Simon Fraser University in Burnaby, Canada. Over the course of hominid evolution, he says, the benefits of the ability to speak could have outweighed the tiny risk that the genes involved in language could malfunction and result in schizophrenia in a small percentage of the population.

Another team, led by human geneticist Renato Polimanti at Yale University in New Haven, Connecticut, is trying to tease out links between environmental factors, mental illnesses and behavioural traits. Polimanti and his colleagues looked at 2,455 DNA samples from individuals at 23 sites across Europe. They quantified each person's overall genetic likelihood of conditions, such as autism, and personality traits, such as extraversion. Then, the scientists calculated whether that risk was associated with certain environmental factors, such as rainfall, winter temperatures or the prevalence of infectious disease - exploring the idea that these factors might have been involved in selecting for the human traits.

People in parts of Europe with relatively lower winter temperatures, they found, were slightly more genetically prone to schizophrenia. Polimanti suggests that if genes that helped people to tolerate cold lay close to variants that promoted schizophrenia, then schizophrenia-related genes could have been inadvertently carried along during evolution as "fellow travellers".

"This was a nice first attempt to put some environmental context" on the genetic variants associated with mental illness, says Tony Capra, an evolutionary geneticist at Vanderbilt University in Nashville, Tennessee. Polimanti plans to repeat the study in other regions.

\section{FOR AND AGAINST}

Untangling the roles of genetics and the environment will be difficult, however, because unknown environmental conditions in the past could have selected for traits that were advantageous then, but are considered negative today. Other evolutionary factors could have had indirect effects. An overactive immune system is thought to be involved in disorders such as depression, but a stronger immune system would have made human ancestors more resistant to diseases, says Stranger.

Some researchers are exploring the evolution of mental illness by looking at possible differences in gene activity in tissues of Neanderthals and humans. A group led by Capra and Vanderbilt geneticist Laura Colbran used modern-human-genome databases to find DNA markers that suggest a gene is differently regulated in various tissues in the body. They then looked for these markers in two Neanderthal genomes. The team found that genes associated with neurological development were regulated differently in the Neanderthal brain and the human brain.

The results could eventually lead to a better understanding of how Neanderthal brains functioned compared with human brains, and whether they might have experienced similar psychiatric disorders.

Studying how mental illness evolved is still in its early stages, but the ability to use massive human-genome databases is an exciting step forward, says Capra. He and his colleagues will take advantage of this by surveying genetic areas that differ between Neanderthals and humans, and searching for differences in how the genes are expressed.

\title{
Turmoil hits science march
}

\section{A group of volunteers claims that the organization that spearheaded global protests in April has been unduly secretive about its management practices.}

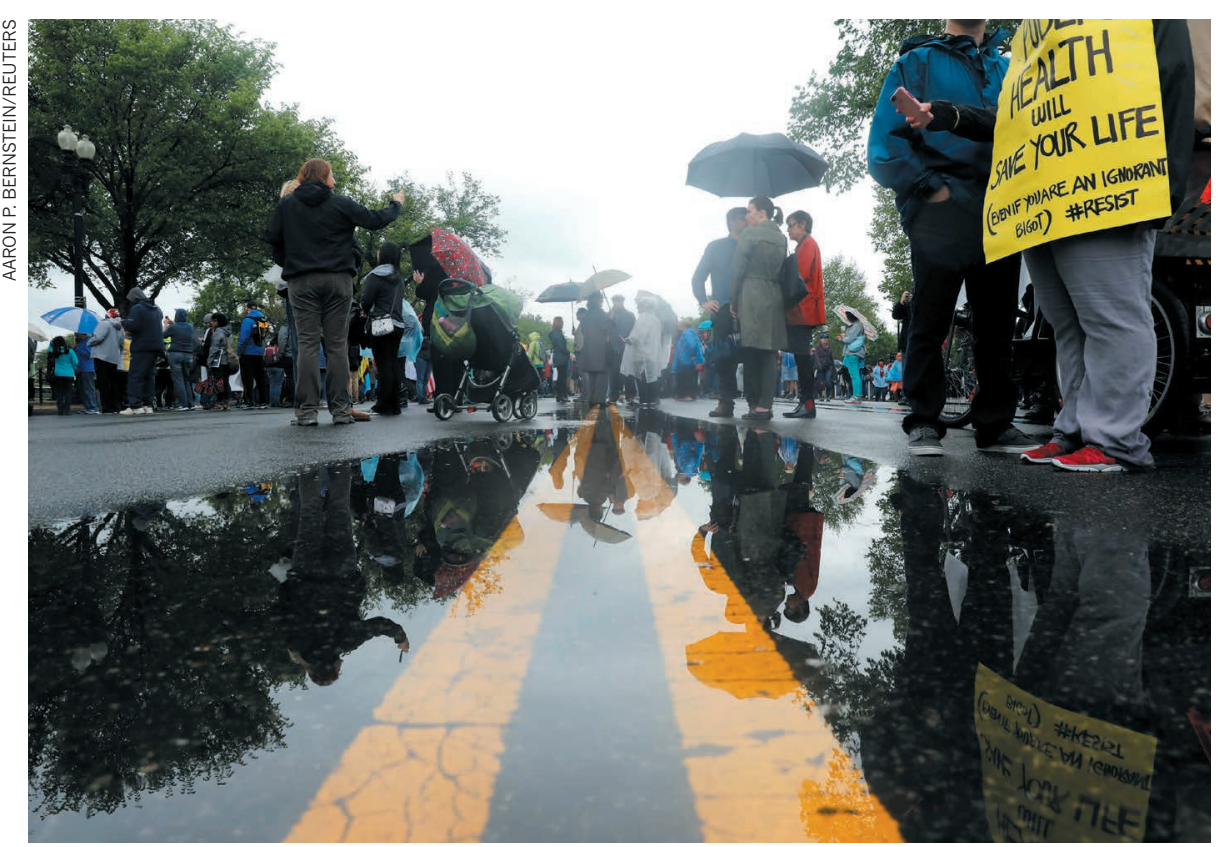

Participants gather at the March for Science in Washington DC on 22 April.

\section{BY EMMA MARRIS}

The US group that sparked the global March for Science movement is facing complaints about its management practices as it files for non-profit status and signals its intent to continue as "a movement to advance science and its role in public life".

On 23 October, a group of current and former volunteers released an open letter to the central March for Science organization in New York City, alleging that it is secretive, insensitive to the concerns of its volunteers and unwilling to share power or information with organizers of its many affiliated 'satellite' groups around the world.

In a statement to Nature, the March for Science said that it welcomed the "concrete feedback and suggestions". But volunteers have already walked away from the organization, and at least one major satellite group, in New York, has severed ties. The turmoil comes at a time of renewed political activism 
by US scientists, much of it in protest against the policies of US President Donald Trump.

Aaron Huertas, the former communications director for March for Science and an author of the letter, says that the organization is becoming hierarchical, rather than the grass-roots movement that many volunteers wanted.

$\mathrm{He}$ and his letter co-signatories are concerned that the group has not published a detailed accounting of its finances, including the US\$1.3 million it raised between 1 February and 30 April. They are uncomfortable with the group's decision to ask some volunteers and board members to sign non-disclosure or confidentiality agreements, and to hire one of the original co-chairs, Caroline Weinberg, as its interim director without advertising the job.

Weinberg says that the board hired her in August as the part-time interim executive director, that a public search for a permanent director will begin in December, and that the March for Science will release more-detailed financial information soon. In the meantime, the disclosure on 24 October that Weinberg and her two co-chairs received money for their services is also coming under scrutiny.

Terry Kush, the March for Science's chief operating officer, revealed the payments in a memo to the organization's satellite groups. "In May and June, 12 national team members were paid for their work those months, including the former cochairs," Kush wrote. She added: "We'd like to reaffirm our commitment to increasing transparency within the org and the larger grass-roots movement."

The group's three original co-chairs Weinberg, Jonathan Berman and Valorie Aquino - resigned from their positions in late April and signed a confidential agreement with the organization in late August, Weinberg says. She adds that although she "cannot comment on the clauses therein", that does not prevent her from being open about "the march, our work, accounting, governance, or legal structures". Aquino and Weinberg also signed what Weinberg calls "standard" confidentiality agreements with the board.

Huertas calls the payments "secret", and argues that not disclosing them publicly undermined the effectiveness of the March for Science group. Weinberg says that the payments were made in July, but not publicly released until now because they took place mid-fiscal year.

"The accusation that we are in this to enrich ourselves and make money is deeply offensive," Weinberg says. "Most people do not have the luxury of volunteering full time." -

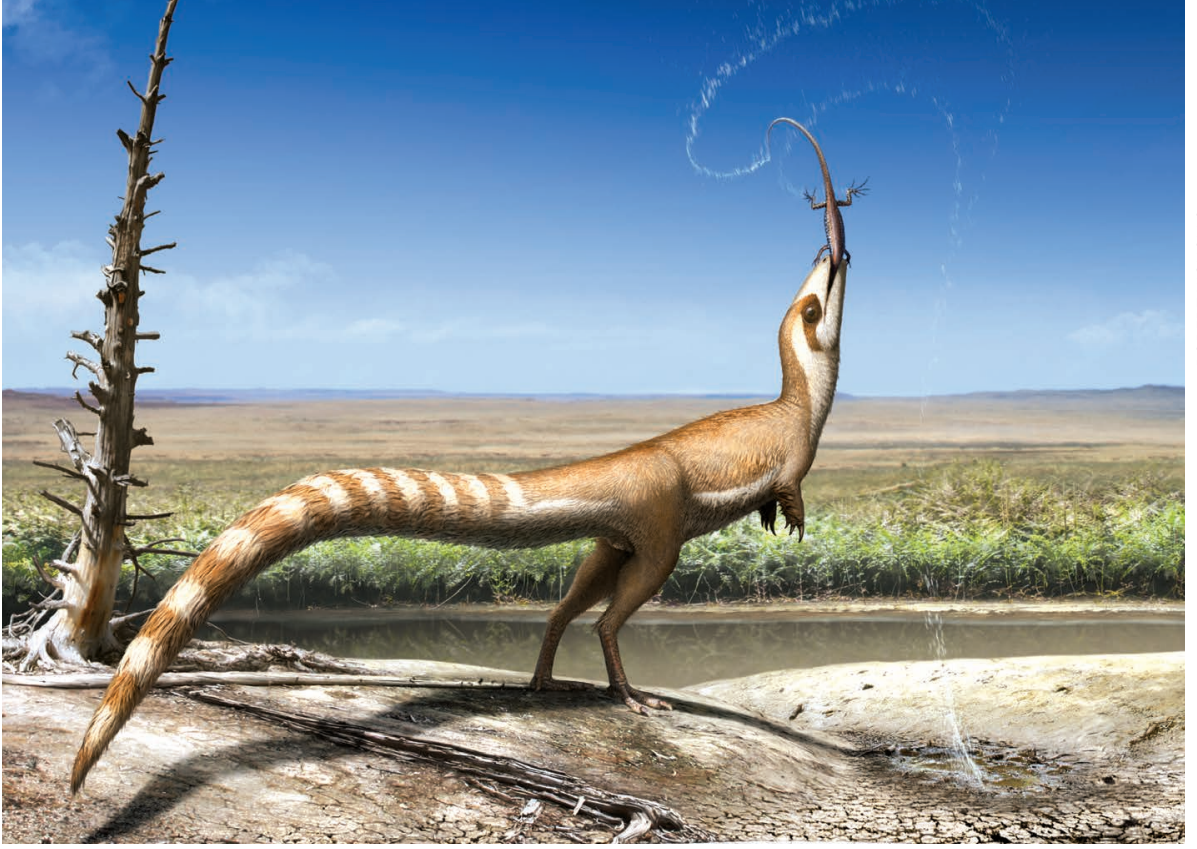

Sinosauropteryx was countershaded, which suggests that it lived in an open habitat (artist's impression).

PALAEONTOLOGY

\section{Dinosaur's feathers cast in new light}

\section{Camouflage plumage patterns hint at carnivore's habitat.}

\section{BY JOHN PICKRELL}

$\mathrm{I}^{\mathrm{s}}$ n 1996, a small, fluffy carnivore called Sinosauropteryx became the first dinosaur known to have had feathers. In 2010, it was one of the first dinosaurs to have its colour elucidated, when an analysis ${ }^{1}$ suggested that it had a ginger-and-white striped tail. Now, researchers have reconstructed the colour pattern across its body. Their findings reveal that Sinosauropteryx was countershaded - dark on top and light underneath. Its face also sported a 'bandit' mask similar to that of a raccoon.

The results, published in Current Biology $y^{2}$ on 26 October, were based on three fossils found in China's northeastern Liaoning Province, on which impressions of feathers and traces of pigmentation had been preserved.

The team, led by Jakob Vinther, a palaeobiologist at the University of Bristol, UK, used high-resolution photography to reveal details of Sinosauropteryx's feathering and coloration. The researchers then created 3D models of the abdomen and photographed them under different lighting conditions. Shadows formed on the models in direct light more closely matched the dinosaur's plumage patterns than those that formed under diffuse light, as found in a forest.

In living species, countershading masks body shape to make animals less conspicuous to predators - but the pattern depends on the environment. By looking at living animals whose dark-light transition occurs high on their flanks, the team determined that
Sinosauropteryx probably lived in open habitat. This pattern better cancels out the 'self-shadowing' on the body that occurs in open areas.

Researchers were also curious about the purpose of the 124-million-year-old dinosaur's bandit mask. In living species, multiple functions for these masks have been proposed, such as reducing glare - something that might have been useful to Sinosauropteryx, whose fossils were deposited in lakeside environments.

Palaeontologist Xing Lida of the China University of Geosciences in Beijing says that advanced microscopy and photography techniques and 3D-imaging technologies are revolutionizing palaeontology. This study and others are helping scientists to develop a more complete picture of the ecosystems of northeastern China in the early Cretaceous period, around 133 million to 120 million years ago, Xing adds.

Michael Pittman, a vertebrate palaeontologist at the University of Hong Kong, says that the team's countershading hypothesis is intriguing. "But it will be nice to see if it holds up with more specimens of Sinosauropteryx and across other theropods," he says.

Vinther has also been involved in research suggesting similar countershading in other species of dinosaur, including a small herbivore called Psittacosaurus and a 1.3-tonne armoured ankylosaur called Borealopelta.

\footnotetext{
1. Zhang, F. et al. Nature 463, 1075-1078 (2010).

2. Smithwick, F. M., Nicholls, R., Cuthill, I. C. \& Vinther, J. Curr. Biol. http://dx.doi.org/10.1016/j. cub.2017.09.032 (2017).
} 